\title{
Study on Measurement of Advanced Manufacturing: Case by China
}

\author{
Jinghuai $\mathrm{She}^{1}$ and Xuedan $\mathrm{Li}^{2 . *}$ \\ ${ }^{1}$ Department of Business Administration, Capital University of Economics and Business, Beijing, China \\ ${ }^{2}$ Department of Business Administration, Capital University of Economics and Business, Beijing, China \\ Corresponding author: dxljyjy@163.com
}

\begin{abstract}
This article has built a system of China's Advanced Manufacturing measurement indicators. By applying the datum from 2004 to 2013, we estimate the level of development and current status of China's Advanced Manufacturing (AM), and evaluate the measurement results by establishing Hierarchical Linear Model (HLM). We confirmed that China's Advanced Manufacturing is in the rapid development trend. And due to the difference of initial conditions in Advanced Manufacturing development there is a greater imbalance. In contrast, a region with poor initial condition of has a relatively fast development speed.
\end{abstract}

\section{Introduction}

Advanced Manufacturing means using IT to propel industrialization, accelerate scientific development and improve industry with high-tech. Not only can advanced manufacturing improve the economic benefits and international competitiveness, but also reduce the consumption of resources, decrease emission of pollution and stick on the way of sustainable development. Judging China's AM development level accurately becomes an important indicator to test the AM and guide developing it, especially the developing status of different regions. This article is based on the background, combined with the industrialized classical theory, while constructing the index system of the AM in China, and applying the statistical datum from 2004 to 2013 to measure the 30 regions in China. Using hierarchical linear models (HLM) statistical methods to evaluate the results. This article has revealed the developing tendency of China's $\mathrm{AM}$ and the developing imbalance in those regions which are caused by the difference of initial conditions, especially those places in disadvantage with a higher speed to develop the industrialization.

\section{Theory and hypothesis}

\subsection{Index system of intelligent manufacturing}

The research of scholars majorly focused on the inevitability, path, content and characteristic of China's AM For example, Lu Zheng (2003) ${ }^{[1]}$, Jiang Xiaojuan (2002) ${ }^{[2]}$, Qu Geping(1998) ${ }^{[3]}$, Wei Liqun (2002) ${ }^{[4]}$, Hu Angang (2003) ${ }^{[5]}$, Jin Bei (2004) ${ }^{[6]}$, Wu Jinglian (2005) ${ }^{[7]}$, Sun Xueguang ${ }^{[8]}$ (2007), etc. They were about how to handle those relations such as a AM and information, resource-environment relationship; also they confirmed how to take and how to realize the AM. Moreover, the study of the GI has promoted the relevant measurement. Such as Cao Jianhai and Li HaiJian(2003) ${ }^{[9]}$, based on input-output method. Xie Delu ${ }^{[10]}(2004)$, Yang Jie(2005) ${ }^{[11]}$, based on characteristics of GI. Wu Xiaoqing(2007) ${ }^{[12]}$, based on the GI connotation; Xie Chun (2011) ${ }^{[13]}$ focuses on technology and resource environment. These studies were growing along from the speed and quality in single angle of industrialization..

$\mathrm{AM}$ revealed the interaction between information and industrialization, and AM is a process which takes the technology progressing as motive force and enhancing economic efficiency and international competitiveness as center. Thus the indicator system should reflect intensive and sustainable developing two factors. In all, based on the predecessors' theories and methods, we extract seven aspects which have the most typical connotation of AM as the sub-elements of the system and recompose them into 35 indicator elements and 50 measurable indicators to reveal the connotation and characteristics of AM.

\section{Data and processing}


This paper applied data from 2004 to 2013, all data are comes from the China statistical Yearbook, Industry statistics report, the science and technology statistical Yearbook, Environmental statistics Yearbook, The ministry of information and industry and other authoritative data. When evaluating the level of AM of China, the paper applied the $2004-2013$ years' data, and standardization the raw data with dimensionless treatment, using a weighted method to calculate the index value of Advanced Manufacturing. Because there is no other means to deal with the original data, the index value represents of China's Advanced Manufacturing during this period, so called "development level"

In the empirical part of this article, the data is from 2002 to 2013. In the seven years, 30 provinces and cities try their best being industrialization which are different in resource endowments, economic development stage, history and geographical situation. We must select an appropriate method to deal with the longitudinal data so that we can analyze green trends as well as industrial growth differences between different provinces. The current method of researching variables growing trend using longitudinal data are Repeated Measures Analysis of Variance, Time Series Analysis and the Hierarchical Linear Model which is relatively late start, but developed rapidly.

\section{Empirical assessment}

Although a detailed analysis have been done from many Angle to China, contained from 2004 to 2013 Advanced Manufacturing stage of development, present development situation, the difference of Advanced Manufacturing level between provinces, the elements of green type industrialization constitution and so on, but the sample value just a symptom of development, the true discipline behind these sample points must through the establishment of the model can get real realization. For example, 30 provinces and cities of China in the process of the Advanced Manufacturing is different or not, whether the initial level of green type industrialization have influence to industrialization process, and how effective of green industrial factors to the Advanced Manufacturing process, all these can be solved only through the establishment of statistical model.

\subsection{HLM}

Through the preliminary analysis of development trend for the 30 provinces and cities, finding that the process of GI development all provinces and cities has a different in development rate and initial development level, that is to say, the intercept and slope is not same in each of the regression model. So, when using the provinces as sample group analysis the regression of the overall country, it is a set of random coefficient regression model, once using the time series model analysis the overall development trend, there will be heteroscedasticity and correlation problem, this will not be able to use OLS effectively estimates parameters, it can't directly use time series model dealing with layer structural data with individual differences. At the same time, because of the repeated measurement of variance analysis used to analysis overall development trends exist limitations, also cannot be used to analysis differences of individual development between regions. Therefore, this study used a green statistical method of data processing track which has been widely accepted - hierarchical linear models (HLM).

The so-called random coefficient regression model mainly set on the second floor of the linear development (growth) model. The second model is the equation about the first layer model intercept and slope, so the second model, without prediction variables, became a purely random effects equation. At this time, the linear development model has become a random coefficient regression model, also can be referred basic linear development model. The basic form is as follows:

The first layer model:

The second layer model:

$$
\text { GI level }=\beta_{0}+\beta_{1}(\text { time })+\mathrm{r}
$$

$$
\begin{aligned}
& { }_{0}=\gamma_{00}+\mu_{0} \\
& { }_{1}=\gamma_{10}+\mu_{1}
\end{aligned}
$$

The equation is an unconditional model, for the second floor, there is no any variables. Although this model did not consider the factor influenced the level of industrialization, but you can use this model and the results analysis the initial level and individual variation, providing a reference for the next evaluation of the second layer model with variables.

In this model, the "time" encoding different variables, the results of model have a different interpretation. If the 2004 year make up for "0", the intercept of first layer model was the average level of Advanced Manufacturing of all provinces in 2004, the slope was units growth rate from 2004 to the next few years; if the 2013 series as " 0 ", the intercept of first layer model was national average of Advanced Manufacturing on the 2013, the slope was unit growth rate after 2013. In this study, two different codes were calculated to last level and initial level to give an explanation.

In this study, the model used the HLM software which is specifically used for calculation of hierarchical linear model, developed by Stephen W. Raudenbush and others. We generated the original data using SPSS13.0 version, and calculated the final result using HLM6.08 version. In order to demonstrate the output in the form HLM6.08 software, using 2004 years as the initial level, we rearrange the output to the general table format according to the software, as shown in Table 1 and Table 2.

Table 1 shows, the estimated average intercept and average slope was 47.4 and 1.2 respectively. The results show that the initial implementation of the Advanced Manufacturing in 2004 the national average was 47.4 industrial units, which means that in 2004 the country's industrialization process has not come to the half, but the average annual growth rate was 1.2 percent after the implementation of the Advanced Manufacturing strategy since 2004, showing that the 
overall level of China's Advanced Manufacturing was a growing trend. Its " $\mathrm{t}$ " value is large enough, and $\mathrm{P}<0.001$, so using these two factors is necessary to describe the growth of China's Advanced Manufacturing.

Table 1 estimated average intercept and slope were 54.7 and 1.2, as the model 2013 Numbers for 0 , the intercept here was the average level of Advanced Manufacturing in 2013, that is to say in 2013, China's Advanced Manufacturing average level has reached 54.7, so only from the results of model, China's Advanced Manufacturing level from the average 47.4 in 2002 have been developed to 54.7. Because average slope is 1.2, it can expect China's Advanced Manufacturing annual growth rate is 1.2 since 2013, and hypothesis that two coefficients of testing results were significantly passing. This confirmed our hypothesis HI.

Table 1. GI model of linear growth (Unconditional, 2004).

\begin{tabular}{|c|c|c|c|c|c|}
\hline Fixed effects & \multicolumn{2}{|c|}{ Coefficient } & S.t error & \multicolumn{2}{|c|}{ t-ratio } \\
\hline $\begin{array}{l}\text { Intercep } \\
\beta_{\mathrm{o}}\end{array}$ & \multicolumn{2}{|l|}{47.371429} & 2.254750 & \multicolumn{2}{|c|}{$21.010 * * *$} \\
\hline $\begin{array}{c}\text { Slope } \\
\boldsymbol{\beta}_{1}\end{array}$ & \multicolumn{2}{|l|}{1.214286} & 0.172327 & \multicolumn{2}{|c|}{$7.046^{* * *}$} \\
\hline \multicolumn{6}{|c|}{$\begin{array}{r}\text { Random effects Variance } \\
\text { Reliability }\end{array}$} \\
\hline $\begin{array}{c}\text { Intercept } \\
u_{0}\end{array}$ & $\begin{array}{c}154.6545 \\
4\end{array}$ & 29 & \multicolumn{2}{|c|}{$\begin{array}{c}1465.78146 * * \\
*\end{array}$} & 0.980 \\
\hline Slope $u_{1}$ & 0.68150 & 29 & \multicolumn{2}{|c|}{$111.30746^{* * *}$} & 0.739 \\
\hline \multicolumn{6}{|c|}{ The first layer of error $r \quad 6.72333$} \\
\hline
\end{tabular}

Table 2, For GI growth model, the variance of the estimated value for the two parameters $\beta_{\mathrm{o}}$ and $\beta_{1}$ are 154.3 and 0.68.In the $\chi^{2}$ test, the $\chi^{2}$-statistic of the two are 1462.2 and 111.3 ,the degree of freedom of the both two are 29 ,both the P values less than 0.001 ,significantly pass. Such results turn out that from 2004 the initial implementation of GI, 30 provinces and cities have existed significant differences, and from the value of variance, the level of GI in 2004 for China's 30 provinces and cities are very significant different. The slope of the variance shows from 2004 to 2013 , seven years of development, the growth rate of 30 provinces and cities exists significant differences. 0.68 form the slope of the variance and standard deviation of 0.82 , so for the specific area, if its growth rate is greater than the average value one standard deviation, it can reach $1.2+0.82=2.02$ percentage points of growth. Of course, for the slow-development region, it will develop by a speed of standard deviation below 1.2 .

Table 2. GI model of linear growth (Unconditional, 2013).

\begin{tabular}{|c|c|c|c|c|c|}
\hline $\begin{array}{l}\text { Fixed effects } \\
\text { ratio }\end{array}$ & \multicolumn{2}{|c|}{ Coefficient } & \multicolumn{2}{|c|}{ S.t error } & t- \\
\hline Intercept $\beta_{0}$ & \multicolumn{2}{|l|}{54.657143} & 2.251987 & \multicolumn{2}{|c|}{$24.271 * * *$} \\
\hline Slope $\boldsymbol{\beta}_{\mathbf{1}}$ & \multicolumn{2}{|l|}{1.214286} & 0.172327 & \multicolumn{2}{|c|}{$7.046^{* * *}$} \\
\hline \multicolumn{4}{|c|}{$\begin{array}{l}\text { Random effects Variance df } \\
\text { Reliability }\end{array}$} & \\
\hline Intercept $u_{0}$ & $\begin{array}{c}154.2682 \\
0\end{array}$ & 29 & \multicolumn{2}{|c|}{$\begin{array}{c}1462.19219^{* *} \\
*\end{array}$} & 0.980 \\
\hline Slope $u_{1}$ & 0.68150 & 29 & \multicolumn{2}{|c|}{$111.30746^{* * *}$} & 0.739 \\
\hline \multicolumn{6}{|c|}{ The first layer of error $r \quad 6.72333$} \\
\hline
\end{tabular}

\subsection{The relations between initial level of regional GI and growth speed}

According to literature, it can get related consistent estimates between initial conditions and real changes by use data repeatedly observed. Studying the relationship between the mentioned two above, generally determined by using the correlation between variance, the formula is :

$$
\hat{\rho}\left(\beta_{0,} \beta_{1}\right)=\hat{\tau}_{01} /\left(\hat{\tau}_{00}+\hat{\tau}_{11}\right)^{1 / 2}
$$


Using equation (4) and HLM6.08 software, calculated the correlation coefficient is -0.202 , as the negative correlation coefficient, the relationship for each region of the growth speed and the initial level of Advanced Manufacturing has a negative relationship, the low initial level of green industrial areas, the development has a faster speed.

\subsection{The study on the influence of regional difference on GI}

Variation of the process of Advanced Manufacturing, what percent are due to regional differences in the level of Advanced Manufacturing is an important issue which is worth focusing on. If regional differences influence on China's overall Advanced Manufacturing level can be reasonably measured, we can base the degree of difference and quantify the contradiction between regional differences in the development and Advanced Manufacturing strategy,. So we can decide how to choose between the two problems.

Hierarchical linear models have a linear cross-level concepts, Cross-level to be addressed is related to the total variance in the dependent variable is due to how many units of the second layer of the model caused by individual differences. The process of calculation is: firstly, the model for the first layer and the second layer of the model were created a pure random model, which can measure separately the random variation of the first and second floors. Among them, the first layer models' random variation is the total variation of dependent, which is caused by the second individual variation. Using the following formula:

$$
\rho=\frac{\tau_{00}}{\tau_{00}+\sigma^{2}}
$$

$\rho$ stand for Cross-class correlation coefficient, ${ }^{\tau_{00}}$ is variance of individual variation, $\sigma^{2}$ is variance of total variation.

Table 3. The first layer and second layer stochastic model calculated results.

\begin{tabular}{|l|l|l|l|l|}
\hline $\begin{array}{l}\text { Random } \\
\text { effects }\end{array}$ & $\begin{array}{l}\text { Varianc } \\
\text { e }\end{array}$ & df & $\chi^{2}$ & $\begin{array}{l}\text { Reliabilit } \\
\text { y }\end{array}$ \\
\hline $\begin{array}{c}\text { The first } \\
\text { layer model }\end{array}$ & $\begin{array}{c}146.9109 \\
9\end{array}$ & 29 & $\begin{array}{c}1821.106 \\
73\end{array}$ & 0.000 \\
\hline $\begin{array}{c}\text { The second } \\
\text { layer model }\end{array}$ & 16.64127 & & & \\
\hline
\end{tabular}

Calculated using the software HLM6.08 the first layer and second layer stochastic model results shown in Table 3, and then use (5) provides the calculation of inter-class correlation formula can calculate the cross-class correlation coefficient of the Advanced Manufacturing was $89.8 \%$, the following formula:

$$
\rho=\frac{\tau_{00}}{\tau_{00}+\sigma^{2}}=\frac{146.91099}{146.91099+16.64127} \times 100=89.8 \%
$$

Among the total variances of the development of Advanced Manufacturing, there are $89.8 \%$ are due to the 30 provinces and cities caused by the difference between the Advanced Manufacturing, which fully shows that the outstanding differences between the China region, while China also shows that green industrial development in narrowing the differences between regions is a very important issue.

\subsection{China's GI initial level and the confidence level of the growth rate}

As already described, reliability is used to describe the estimation accuracy. of model. Estimation accuracy of a model calculation for testing the validity of the model is very important because if the model parameters estimated from the variation of most of the errors caused by the model itself, then this model will be very unreliable, the use of such model for China's Advanced Manufacturing level of analysis, would be a mistake. Reliability is the variance divided by the estimated parameter variance, total variance equal to the parameter estimation error variance and the sum. With the formula is:

$$
\begin{aligned}
& \operatorname{reliability}\left(\beta_{0 j}\right)=\tau_{00} /\left(\tau_{00}+\nu_{00}\right) \\
& \operatorname{reliability}\left(\beta_{1 j}\right)=\tau_{11} /\left(\tau_{11}+v_{1 j}\right)
\end{aligned}
$$

Table 1 has been the reliability of the results list, the reliability of the intercept and slope of 0.980 and 0.739 , respectively, belong to the relatively high credibility. The results show that both the intercept and the slope, the data have sufficient amount of information, each parameter can be as individual-level variables for modeling.

About the size of reliability, Raudenbush et al. (2004) described, usually, lower reliability does not prove that the statistical analysis carried out is not valid. Only when the reliability is very small, such as less than 0.1 , research indicates that only the best will in the random coefficients as fixed factors, random items will be removed in order to facilitate subsequent model analysis. 


\subsection{The empirical results}

Empirical results support our all previous assumptions, as follows:

-The average growth trajectory of China's Advanced Manufacturing from 2002 to 2013 shows sustained steady upward trend. The strategy implementation process of Advanced Manufacturing from 2004 to 2013, China's total Advanced Manufacturing level made a steady effects, Advanced Manufacturing index rise 54\% in 2004 to $63 \%$ in 2013, while most of the provinces' Advanced Manufacturing level has considerable progress, although the albeit is different, the growth effect is obvious.

-There are large regional differences in China's Advanced Manufacturing. The results of the hierarchical model, the model intercept and slope variance test have passed a significant test, which means that the variance is significantly different from 0 . From the perspective of the slope, the slope of the different provinces exist big differences, that is to say the green industrial growth in each region is very different..

- The initial level of industrialization and development rate within a certain range shows negative correlation. Pace of development of Advanced Manufacturing and regional initial level in a certain range exist negative correlation, the correlation coefficient is -0.202 . In other words, the initial low level of green industrial areas, the growth rate slightly faster, but the initial high level of regional growth at a slower pace.

\section{Conclusions}

This article measured the development level and status of China's Advanced Manufacturing by building index system. And give evaluation, analysis and reasonable explanation on the development trend of China's Advanced Manufacturing and the effects that basic conditions will have on the Advanced Manufacturing of 30 areas by using hierarchical linear models (HLM) statistical methods. In our opinion, as regional differences have big influence on the development of Advanced Manufacturing, the government should plan the development policies of Advanced Manufacturing for different regions and promote the coordinated development; In addition, in the process of Advanced Manufacturing, because of different regional conditions, we do not take the same road, according to the different regional resource endowments and historical conditions, we can follow our own pattern to achieve success.

\section{Acknowledgement}

The work described in this paper was supported by the National Social Science Foundation of China (No: 14BGL214) and the Science Foundation of Ministry of Education of China (No.13YJA630073).

\section{References}

1. Lv Z, Research on Chinese intelligent Manufacturing, Economy and Management Research, No. 2, 3-6 (2003).

2. XJ Jiang, Intelligent Manufacturing: the only way leading to XiaoKang life, RenMin.form., No.12, 4-6 (2002).

3. Qu GP, Chinese industrialization and environment protection, Chinese population, resources and environment, No. 2, 1-4 (1998).

4. Wei LQ, Stick to the way of intelligent Manufacturing, Econ.Times, No. 23, 17-20 (2002).

5. $\mathrm{Hu} \mathrm{AG}$, Wen $\mathrm{J}$, China modernization pursuing in national regions: effect, characteristics, causes and its consequences, Guangxi. Univer. Nation. J, No. 1, 107-114 (2003).

6. Jin B, Several theoretical issues about intelligent Manufacturing, Chongqing. Tech. Busi. UIMversity Press (social science edition), Vol. 21, No. 3, 5-8 (2004).

7. Wu JL, Misunderstandings and distortions about intelligent Manufacturing, Busi. Week. J, No. 16, (2005).

8. XG Sun, Research on connotation and scientific advance of the new industrialization, China National Conditions and Strength, No. 10,18-20(2007).

9. JH Cao, $\mathrm{HJ} \mathrm{Li}$, The theory of new industrialization road, Chinese industrial economy, No.1,56-62(2003).

10. Xie DL, Li Q, Wang XM, Analysis of index system for intelligent Manufacturing and evaluation standards, Reform, No. 4, 30-38(2004).

11. Yang J, Luo ZH, Zhang CY, Research on evaluation index system of the new industrialization, Jilin. Univer. J ( Social Sciences Edition), No. 3, 124-129(2005).

12. Wu XQ, Research on evaluation index system and model construction of new industrialization process in China, Chongqing University, (2007).

13. Xie C, Li J, The building and empirical analysis about evaluation index system of Chinese new characteristics industrialization, Syst. Engin. J, No. 3, 74-80(2011). 